\title{
CONTRIBUIÇÕES DA DISCURSIVIDADE PARA A CONSTRUÇÃO DE REPOSITÓRIOS DIGITAIS
}

\author{
CONTRIBUCIONES DE LA DISCURSIVIDAD \\ PARA LA CONSTRUCCIÓN DE REPOSITÓRIOS \\ DIGITALES
}

\begin{abstract}
Clóvis Ricardo Montenegro de Lima - clovismlima@gmail.com Pós-doutor em Ciência da Informação pelo Instituto Brasileiro de Informação em Ciência e Tecnologia (IBICT). Pesquisador do Instituto Brasileiro de Informação em Ciência e Tecnologia/Universidade Federal do Rio de Janeiro (IBICT/UFRJ).

Jobson Francisco da Silva Júnior - jobsonminduim@gmail.com Doutorando do Programa de Pós-Graduação em Ciência da Informação do Instituto Brasileiro de Informação em Ciência e Tecnologia/Universidade Federal do Rio de Janeiro (IBICT/UFRJ).

Márcio da Silva Finamor - marciofinamor@gmail.com Mestrando do Programa de Pós-Graduação em Ciência da Informação do Instituto Brasileiro de Informação em Ciência e Tecnologia/Universidade Federal do Rio de Janeiro (IBICT/UFRJ).
\end{abstract}

\footnotetext{
RESUMO

Introdução: Nesta pesquisa discute-se a (re)construção dos repositórios digitais, usando como exemplo o Repositório Institucional Digital do Instituto Brasileiro de Informação em Ciência e Tecnologia - RIDI, sob a perspectiva da discursividade com a adoção da Teoria do Agir Comunicativo (TAC) de Jürgen Habermas.

Objetivo: Propor o diálogo - entendimento mútuo - como um dispositivo para compreender quais seriam as contribuições de se adotar uma abordagem discursiva para a implementação de repositórios digitais.

Metodologia: Adota uma abordagem crítica fundamentada na teoria de Habermas para discutir o agir comunicativo e a humanização nas organizações.

Resultados: Observa-se que a adoção de uma abordagem discursiva apresenta potencialidades para se repensar a implementação e a manutenção dos repositórios digitais.

Conclusões: Reflete sobre a constituição de repositórios digitais, e questões correlatas como suas políticas de preservação, e aponta a mediação como uma forma de otimizar a implementação dos mesmos.
} 
Palavras-chave: Habermas. Racionalização discursiva. Humanização nas organizações. Repositórios Institucionais.

\section{INTRODUÇÃO}

Ao observarmos a implementação e manutenção dos repositórios digitais, hoje, é facilmente identificável uma séria de questões que podem ser repensadas para a otimização desta ferramenta, desde a própria elaboração do repositório (desenvolvimento e/ou customização do software) a questões como as políticas de acesso, preservação e também questões relativas aos direitos autorais dos documentos disponibilizados, tomando essas questões como ponto de partida vemos como uma possível solução para estas questões a implementação dos repositórios digitais a partir de um ambiente conversacional.

Para isso, destaca-se a Teoria do Agir Comunicativo (TAC), de Habermas, como método para (re)construção de repositórios digitais. $\mathrm{O}$ fundamento dessa teoria está pautado na interação dos envolvidos e, no entendimento mútuo, dos processos de gerenciamento humanístico em qualquer ambiente organizacional. Ou melhor, em processos de gerenciamento organizacional com o víeis humanístico. Partindo desse princípio, procurou-se aplicar a TAC nesse estudo a respeito da constituição dos repositórios, seja em seu desenvolvimento ou em seus processamentos técnicos específicos. Busca-se estabelecer critérios para que haja um consenso entre os indivíduos no que diz respeito à criação de políticas, nos processos que envolvem serviços e na execução das atividades. Através dos atos de fala: em que se estabeleça a conformidade entre os indivíduos no ambiente das atividades, para chegar ao melhor argumento na consecução de determinado serviço; processos; criação das políticas; dentro da concepção dos repositórios digitais.

O conceito do agir comunicativo refere-se à interação de pelo menos dois sujeitos capazes de falar e agir estabelecendo uma relação interpessoal (seja por meios verbais ou extraverbais). Os atores buscam 
um entendimento da situação para, de maneira concordante, coordenar seus planos de ação e, com isso, suas ações (HABERMAS, 2012, p. 166).

Em esclarecimento inicial, e significativo, para que seja factível desenvolver repositórios institucionais adequados a políticas e a modelos específicos e que, ao mesmo tempo, acomodem a pluralidade de interesses das diversas comunidades, é necessário adotar plataformas de software versáteis, com capacidade de expansão e de integração a outros programas que possam apoiar o atendimento às demandas atuais e futuras. Adicionalmente, é necessário ainda incluir uma dimensão voltada para a gestão e administração do repositório que incluem, por exemplo, a gestão de direitos e de acesso, da preservação digital, das coleções, da segurança da informação, e ainda os instrumentos de gestão voltados para o usuário final (MARCONDES; SAYÃO, 2009).

O desenvolvimento dos repositórios, dos conhecimentos científicos e técnicos, que propiciam o crescimento e o aperfeiçoamento das forças produtivas, provê o sistema capitalista de um mecanismo regular que assegura a sua manutenção sem estar isento de crises. Desta forma, "se institucionaliza a introdução de novas tecnologias e de novas estratégias", isto é, "institucionaliza-se a inovação enquanto tal", cumprindo a ciência e a técnica o papel de legitimar a dominação (HABERMAS, 1987b, p. 62).

Pois, "esses sistemas são os inibidores da ação comunicativa do discurso". É necessário retirar essas barreiras que impedem a interação e a comunicação que estão presentes dentro do ambiente de trabalho, como: autoridade, competitividade e atritos, dentre outros. Pelo contrário, construir pontes para a interação e socialização, através do diálogo e do consenso entre as partes, estabelecer a humanização nas organizações e, consequentemente, uma maior colaboração da rede de equipe.

As pessoas em suas atividades conhecem seus serviços e estão familiarizados com a técnica, dessa forma, com o tempo adquirem novas 
experiências e podem colaborar com aquilo que sabem e aquilo que vivenciaram. Sabendo que tal norma ou prática se mudasse, aprimoraria a forma como era conduzida, assim, melhorando os processos e serviços, sobre outro olhar mais curado. Daí que surge, a necessidade de interação e o diálogo para a formulação e aprimoramento dos serviços.

A proposta, da ideia da meta do entendimento [na ação comunicativa]. Isto é, a produção de um acordo, que reside na compreensão mútua da comunidade intersubjetiva, do saber compartilhado, da confiança recíproca e da concordância de uns e outros. O acordo através da discursividade descansa sobre a base do reconhecimento das quatro correspondentes pretensões de validez: inteligibilidade, verdade, sinceridade e retidão (HABERMAS, 1989).

Sob o olhar tecnológico dos repositórios e dentre as pretensões de validez: o discurso aqui é concebido num sentido cultural abrangente, na medida em que visa, em parte, a formação de preferências e de convicções, e não apenas a agregação de interesses para competição. Ao invés de pensar a deliberação como o resultado de um encontro dialógico singular (o ato de fala que acontece através da internet), podemos pensar as condições da deliberação numa dimensão cultural mais ampla e cooperativa (MAIA, 2010).

\section{DISCURSO: UM MÉTODO PARA A ADMINISTRAÇÃO DAS ORGANIZAÇÕES COMPLEXAS E SUA HUMANIZAÇÃO}

"Verständigung" é um conceito Habermasiano, que traduzido do alemão para o português significa: chegar a um entendimento (ARAGÃO, 1992, p. 39). E esse entendimento se dá por meio do diálogo - ponto central desse artigo - através do uso da linguagem (no uso social) como representação, interpretação e na comunicação dos atos de fala, através dos argumentos e pontos de vistas na construção das idéias e resolução dos problemas.

Habermas (1989) assemelha-se o discurso como as 
argumentações. Tal como: ilhas ameaçadas de se verem submersas pelas ondas no oceano de uma prática, onde o modelo da solução consensual dos conflitos de ação, não é de modo algo dominante. Os meios de entendimento mútuo não cessam de se verem desalojados pelos instrumentos da violência. A ação do agir, que se guia por princípios éticos tem que se arranjar com os imperativos resultantes das imposições estratégicas. É nesta espécie de restrição ao discurso que o poder dos fatos se faz valer em face das pretensões e interesses transcendentes da razão.

O autor acrescenta que essas premissas derivam de um princípio moral universal da ética do discurso e que essa concepção se diferencia de outras perspectivas pelo seu caráter procedimental, ao invés de se construir a partir de conteúdos normativos. Toda norma válida tem que preencher a condição de que as consequências e efeitos colaterais, que previsivelmente resultem de sua observância universal para a satisfação dos interesses de todo indivíduo, possam ser aceitas sem coação por todos os concernidos (HABERMAS, 1989).

Um dos aspectos fundamentais a necessidade de resoluções dos problemas organizacionais está na argumentação consistente e elaborada. Estabelecendo o melhor argumento (consenso mútuo), através da exposição das opiniões entre os indivíduos, seja através do discurso prático ${ }^{1}$, explicativo ${ }^{2}$ ou teórico ${ }^{3}$. A importância está na existência do diálogo nas organizações e nos processos.

Ao estabelecer o ato de fala, inicia-se uma relação intersubjetiva entre falante e ouvinte $\mathrm{e}$, ao mesmo tempo, numa relação objetiva com o mundo. Ao se conceber o entendimento mútuo como telos inerente à linguagem, impõe-se a co-originalidade de representação, comunicação

\footnotetext{
${ }^{1} \mathrm{O}$ discurso prático, com pretensão à correção das normas. É racional aquele que justifica suas ações e julga com imparcialidade;

2 O discurso explicativo, com pretensão à compreensibilidade. É racional aquele que forma adequadamente suas construções simbólicas e se dispõe a explicar o significado de suas expressões; e

${ }^{3} \mathrm{O}$ discurso teórico, com pretensão à verdade ou eficácia dos fatos. Aqui, racional é aquele que profere opiniões fundamentadas e age com eficiência. (HABERMAS, 1987, p. 38-42 apud ALVES, 2009, p. 190).
} 
e ação. Uma pessoa entende-se com outra sobre alguma coisa no mundo. Como representação e como ato comunicativo, dado que, a articulação linguística aponta em duas direções ao mesmo tempo: o mundo e o destinatário (HABERMAS, 2004).

Vizeu (2009) considera a linguagem como atributo essencial na construção de significados. E a comunicação como um processo que assume um novo patamar na compreensão da realidade organizacional. Em outras palavras, grande parte do que é a organização e dos processos gerenciais e técnicos, podem ser definidos pela interação comunicativa entre seus membros e entre estes e os seus públicos externos (real e virtual). É a partir desta interação comunicativa que as visões de mundo feitas por estes distintos grupos internos e externos são (re)construídas. Tendo em conta que tais percepções orientam a ação social, podemos inferir que a dinâmica da atividade organizacional cotidiana é, essencialmente, definida pelas interações comunicativas das pessoas e grupos participantes.

Habermas (1989) considera as interações comunicativas como aquelas nas quais as pessoas envolvidas se põem de acordo para coordenarem seus planos de ação, o acordo alcançado em cada caso, medindo-se pelo reconhecimento intersubjetivo das pretensões de validez. No caso dos processos de entendimento mútuo linguísticos, os atores erguem com seus atos de fala, ao se entenderem uns com os outros sobre algo, pretensões de validez, mais precisamente, pretensões de verdade, de correção e de sinceridade, conforme se refiram a algo no mundo objetivo, no mundo social comum e no mundo subjetivo próprio.

A partir do momento em que entendemos a socialização intencional do mundo como: mediada através da comunicação, não contamos mais com seres inteligíveis, oniscientes, sem corpo e que agem fora de um contexto; porém com atores ligados a um corpo, socializado em formas de vida concretas, localizados no tempo histórico e no espaço social, envolvidos nas redes do agir comunicativo, os quais, ao interpretar provisoriamente a respectiva situação, têm que alimentar- 
se das fontes indisponíveis de seu mundo da vida (HABERMAS, 2010).

Mesmo em tais condições ideais de discursos e negociações, só podem desenvolver sua capacidade de solucionar problemas, na medida em que os problemas em foco forem captados de modo sensível, à luz de tradições pós-tradicionais reflexivas, descritos adequadamente e respondidos de forma produtiva. Um entendimento discursivo garante $\mathrm{o}$ tratamento racional de temas, argumentos $\mathrm{e}$ informações; todavia, ele depende de contextos de uma cultura e de pessoas capazes de aprender. Ou seja, a visão de mundo na forma dogmática e de padrões rígidos na socialização podem constituir obstáculos para um modo de socialização discursiva (HABERMAS, 2010).

A ideia do discurso, como conduta para uma administração nas organizações, é uma abordagem ainda pouco usada na prática. As organizações ainda trabalham em fronteiras rígidas, entre departamentos e processos de produção fechada e mecânica, onde inibem as pessoas a tomarem iniciativas de socialização e inovação. A idealização de substituir esse modelo organizacional, por fronteiras permeáveis, flexíveis, com mobilidade suficiente para reagir às mudanças impostas pelo ambiente externo num modelo discursivo. Como o bom relacionamento e a ligação dos membros, através da visão e do debate humanístico para uma maior transparência na comunicação e ampliação da racionalização. Sendo esse caminho como argumento para as organizações fazer de seus processos e serviços inovadores e coletivos. Ou seja, a administração das organizações sobre o método de um acordo em comum entre os envolvidos. Isto é, o reconhecimento e a prática de que "A natureza das humanizações nas organizações se da na construção dela em torno das pessoas." (MORGAN, 2006, p. 142).

Como bem colocam os autores Lima, Carvalho e Lima (2010, p. 15), sobre a questão do discurso nas organizações como o elemento chave para uma organização rica, pois, uma vez que: 
A perda da autonomia de falar nas organizações resulta no empobrecimento de valores e conhecimentos, e também na redução dos vínculos solidários entre os que trabalham. As reduções têm um custo: qualquer racionalização de processos, melhoria ou inovação nas organizações requer investimentos para a introdução de novos conhecimentos. A aprendizagem das organizações com seus próprios processos se perdem neste silêncio. O comando externo na perspectiva do observador implica em custos para apropriação, aceitação e legitimidade dos novos conhecimentos. Treinamento e motivação são ferramentas necessárias para quem faz calar os participantes dos processos produtivos. O Discurso amplia as perspectivas de representação de interesses nas organizações, politizando suas decisões e possibilitando a racionalização mediadora discursiva. O Discurso tem papel ativo na transformação das organizações, valorizando e viabilizando expressão e comunicação entre os que participam dos processos produtivos. A ampliação da expressão das perspectivas e a viabilidade da comunicação que vão proporcionar a aprendizagem a partir dos próprios processos produtivos.

Para fortalecer a participação igualitária, são necessárias não apenas estruturas comunicacionais eficientes, ou instituições propícias à participação, mas também devem estar presentes a motivação correta, o interesse e a disponibilidade dos próprios cidadãos para se engajar em debates. As novas aplicações tecnológicas, independentemente de favorecer ou dificultar a democracia, devem ser pensadas de maneira associada com os elementos sócio-históricos próprios dos atores sociais e com os procedimentos da comunicação estabelecida entre os sujeitos comunicantes concretos (MAIA, 2010).

A título de exemplo, se a discussão acontece em um ambiente livre de medo, de intimidação ou de ridículo, uma variedade maior de pontos de vista pode ser expressa tanto virtualmente, como pessoalmente. Do ponto de vista virtual, a "força do melhor argumento", que não guarda uma relação com o papel social dos participantes, tem maiores chances de se impor num fórum público virtual (MAIA, 2010).

Habermas (1990) distingue diferentes tipos de interação: primeiro lugar, de acordo com o mecanismo de coordenação da ação; é preciso 
saber, antes de mais nada, se a linguagem natural é utilizada apenas como meio para transmissão de informações ou também como fonte de integração social nesse caso trata-se, do agir estratégico. No segundo caso, a força consensual do entendimento linguístico, isto é, as energias de ligação da própria linguagem, tornam-se efetivas para a coordenação das ações, ao passo que no primeiro caso o efeito de coordenação depende da influência dos atores uns sobre os outros e sobre a situação da ação, a qual é veiculada através de atividades não linguísticas que é do agir comunicativo.

Iniciativas de Democracia Digital contemplam princípios, práticas e valores tão importantes quanto ou mesmo moderadores das qualidades da participação. Tão valioso quanto aproximar os cidadãos de processos de tomada de decisão é muni-los de informações relevantes, qualificadas e compreensíveis, de modo a promover o maior nível possível de transparência (AGGIO; SAMPAIO, 2013).

Seguindo nessa direção, voltando aos repositórios digitais, novos padrões, procedimentos técnicos e gerenciais estão surgindo na constituição de repositórios; esquemas de representação e de arquivamento, recuperação e disseminação estão sendo reconfigurados, tendo como pano de fundo o movimento de acesso livre às informações científicas, que estende rapidamente a sua pauta de interesse para as questões de acesso aos dados de pesquisa, enquanto parte essencial da memória científica mundial. Pelo lado mais pragmático e operacional, um conjunto de atividades gerenciais, técnicas e informacionais fortemente padronizadas chamado coletivamente de curadoria de dados $^{4}$ de pesquisa, permite que os dados possam ser tratados,

\footnotetext{
${ }^{4}$ Curadoria de dados de pesquisa: é a contribuição para o estabelecimento de um modelo de curadoria digital no país. Ela emerge como uma nova área de práticas e de pesquisa de espectro amplo que dialoga com várias disciplinas e muitos gêneros de profissionais. Assegura a sustentabilidade dos dados para o futuro, não deixando, entretanto, de conferir valor imediato a eles para os seus criadores e para os seus usuários. Facilitam o acesso persistente a dados digitais confiáveis por meio da melhoria da qualidade desses dados, do seu contexto de pesquisa e da checagem de autenticidade. Dessa forma, contribui para assegurar a esses dados validade como registros arquivísticos, significando que eles podem ser usados no futuro como evidência legal. $O$ uso de padrões comuns entre diferentes conjuntos de dados,
} 
arquivados em ambientes digitais confiáveis, preservados e reconfigurados de forma que possam ser aplicados em novos contextos científicos; sirvam de base para novas pesquisas; sejam aproveitados para fins educacionais; e, sobretudo, colaborem para minimizar a duplicação de esforços nas estratégias de criação de dados (SAYÃO; SALES, 2013).

A implementação desses novos padrões que surgem a cada dia, seja técnico ou tecnológico, é algo inevitável nas Instituições que permeiam a constituição dos repositórios. Um dos desafios, nos processamentos técnicos e tecnológicos, está na interação tecnológica (interoperabilidade) entre repositórios no Brasil. $E$ na questão da comunicação e satisfação do usuário (plataforma intuitiva). Com o apoio da teoria da ação que tem como foco a melhoria dos processos e inovação, dessa forma, instrui-se o uso da discursividade e na transparência das comunicações para aperfeiçoar os processos, no repensar do uso da tecnologia e na dependência de sistemas, nos serviços, no planejamento das políticas entre outros, para a constituição de repositórios.

Habermas (2012) afirma que só funciona como mecanismo de coordenação da ação do agir, à medida que os participantes da interação se põem de acordo quanto à validade pretendida para suas interações, ou seja, à medida que reconhecem intersubjetivamente as pretensões de validade.

Um último ponto de aproximação dessa teoria está na perspectiva de liderança. Onde consiste a transformação e na construção de uma relação em que permite enxergar o outro como um participante legítimo

proporcionado pela curadoria digital, cria mais oportunidades de buscas transversais e de colaboração. O outro elemento básico desse modelo são as ações que devem ser tomadas no decorrer do processo de curadoria. Em três tipos como: ações para todo o ciclo de vida; ações sequenciais e ações ocasionais. Essas ações, para cada uma, existem uma lista de normas, para agir especificamente, incluso no artigo: "Curadoria Digital: um novo patamar para preservação de dados digitais de pesquisa" desses autores. Esse modelo permite uma visão coletiva sobre o conjunto de funções necessárias à curadoria e à preservação de dados de pesquisa. Além de definir papeis, responsabilidades e conceitos, ele explicita a infraestrutura de padronização e as tecnologias que devem ser implementadas (SAYÃO; SALES, 2012, p. 184-187, grifo dos autores). 
da organização, onde se estabelece a interação social. Para isso, a ênfase na comunicação e nos diálogos orientados para o reconhecimento do outro está presente tanto na TAC, quanto no modelo da liderança transformacional. A ação comunicativa somente se estabelece quando há o reconhecimento do outro como um sujeito com poder de participação legítimo, e isso só ocorre quando há o reconhecimento das motivações do outro - no mínimo, quando há a intenção desse reconhecimento (VIZEU, 2011).

Os processos de entendimento mútuo visam um acordo que depende do assentimento racionalmente motivado ao conteúdo de um proferimento. $\mathrm{O}$ acordo não pode ser imposto à outra parte, não pode ser extorquido ao adversário por meio de manipulações: o que manifestamente advém graças a uma intervenção externa não pode ser tido na conta de um acordo. Este assenta-se sempre em convicções comuns (HABERMAS, 1989).

A força decisiva nessas negociações é a comunicação. Os projetos $e$ as soluções somente se tornam racionalmente compreensíveis através de práticas interativas concretas, que inclui normas institucionalizadas e negociações pragmáticas. Os atores podem beneficiar-se da comunicação mais horizontal e interativa proporcionada pelas novas tecnologias da informação; podem beneficiar-se da redução de custos propiciada pela internet para se auto-organizar, coordenar a ação coletiva, bem como para produzir e distribuir material informativo de maneira autônoma (MAIA, 2010).

Os interesses não existem antecipada ou independentemente de sua articulação no discurso. Os atores devem, sobretudo, elaborar uma metalinguagem, a fim de relacionar os problemas práticos de suas causas ao conjunto de categorias simbólicas da sociedade, bem como ao sistema normativo. Devem estabelecer pontes comunicativas entre os diferentes atores sociais e ambientes de conhecimento. Devem ser convincentes para interferir nos consensos éticos que orientam a coexistência social e articular, de modo consequente, demandas específicas, a fim de que possam ser mais facilmente encampadas 
pelas Instituições Políticas (MAIA, 2010).

Em vias de projeção de uma organização onde a comunicação se dá sem barreiras, com um envolvimento multidisciplinar para fazer pensar e agir na resolução de problemas. Em uma organização num modelo horizontal que se constitui mais flexível e mais dinâmica. Sem proliferação de níveis hierárquicos, sequer autocráticos. Mas sim, dialógica e discursiva entre as redes de equipes para fazer de suas atividades criativas e inovadoras.

Dessa maneira, defendemos aqui que iniciativas da discursividade e da administração horizontalizada é uma das estruturas e mecanismos existentes para uma orientação democrática, onde se encontra meios para a construção e (re)construção de repositórios digitais. Por essas razões, concentraremos nossos esforços na perspectiva da Teoria do Agir Comunicativo.

Esse modo de participação, essencialmente, permite convocar os indivíduos a dialogar e se entender mutuamente. Dessa forma, estabelecendo compromissos nos processos organizacionais do programa. Sendo o processo relevante e, consequentemente, resultando em atributos consistentes e duradouros. Sem o processo, não se tem o produto de qualidade. $\mathrm{E}$ um bom processo organizacional se dá por meio do envolvimento com a equipe, ou seja, pelos discursos e diálogos.

Esta constatação leva à questão acerca dos efeitos do modelo consultivo do Repositório Institucional Digital (RIDI) do Instituto Brasileiro de Informação em Ciência e Tecnologia (IBICT). Na repercussão como modelo admissível para a construção dos repositórios digitais no país. Sob o ponto de vista do agir comunicativo para as aplicações da teoria Habermasiana.

Esse repositório tem o encargo de disponibilizar um acervo crescente das publicações científicas produzidas no Instituto. O principal objetivo do RIDI é armazenar, preservar, divulgar, dar acesso à produção intelectual do IBICT, proporcionando uma maior visibilidade e maximizando os impactos da pesquisa como parte do movimento pelo 
Acesso Livre à informação (IBICT, 2015).

Em relação ao $D$ Space é o software predominante. Que é usado pelo RIDI. Sendo esse, um sistema desenvolvido pelo MIT em parceria com a Hewlett-Packard Company (HP), e é distribuído no Brasil pelo IBICT, que capacita as Instituições em sua implementação, oferece suporte técnico e incentiva a publicação de materiais de apoio em português, fundamentando a predominância desse software no território nacional, o que reforça escolha desse repositório. A ampla adoção do DSpace, no Brasil, é explicada por Murakami e Fausto (2013) quando afirma que o engajamento de um órgão oficial na distribuição do software de repositórios influencia o sistema predominante em determinado país.

Portanto, um fator determinante na viabilização dessas dimensões e modelo é a qualidade da plataforma do software e a sua adequabilidade aos requisitos funcionais sobre a qual o repositório irá operar. Portanto, o desafio de selecionar uma plataforma de software como parte do ciclo de planejamento de repositórios institucionais tornase uma fase crítica para o sucesso do empreendimento (MARCONDES, SAYÃO, 2009).

A questão das tecnologias e softwares é de fato proveitosa e essencial para o desenvolvimento de repositórios. A tecnologia da informação e seus componentes são cruciais nesse processo, pois, permitem a disseminação da produção científica em formato digital, no acesso rápido em qualquer parte do mundo, do suporte para as informações, registro, preservação e recuperação da informação científica.

No entanto, a velocidade do crescimento tecnológico e a dificuldade de acompanhamento das modernas tecnologias é algo a ser discutido. Dado que, o alto investimento em tecnologia, seu desenvolvimento é de tal magnitude, que quando adquirir o software e até implantar, processar, treinar todos os envolvidos, no final desse processo a tecnologia já pode está ultrapassada. Resultando na perda de tempo, no esforço e empreendimento que pode não ser mais 
aproveitado e do custo para o desenvolvimento tecnológico.

A melhor forma de lidar com isso seria o uso de plataformas livres (software livre). Existe nele o seu custo e manutenção como qualquer custo tecnológico. No entanto, a idéia de ser um modelo livre, para a organização construir de acordo com suas necessidades e interesses funcionais e, principalmente, longe de ser substituído por outra tecnologia parece ser incontestável. Com o modelo de software livre customizado - onde consegue priorizar os sistemas e as Instituições a trabalharem em conjunto, o que remete a questão da interoperabilidade. Já que, esse, é um dos grandes desafios para a construção de repositórios: a escolha da plataforma.

Com base na literatura sobre repositórios, outros problemas mais frequentes e entre os mais aludidos, estão a preservação, as políticas (normas) e a tecnologia (interoperabilidade) e o direito autoral.

Sobre a questão da preservação Hollós (2010), ressalta que a preservação documental e (digital) deve ser entendida como uma atividade multidisciplinar. Para isso, a atualização de alguns conceitos e posturas relacionados à preservação, como a própria mudança de olhar do conservador: um olhar ampliado que busca a convergência de visão e valores, voltados a estratégias e ações integradas de preservação sistêmica. Isto é, a preservação, para além da conservação física dos suportes materiais, como parte de um corpo representado também pela gestão, o acesso e a difusão da informação e do conhecimento (HOLLÓS, 2010). No caso dos documentos analógicos, preservação do suporte e sua forma física asseguram a conservação do conteúdo, porém, a mesma situação não se aplica a documentos digitais (WEITZEL; MESQUITA, 2015).

Em que, os equipamentos e softwares utilizados são substituídos rapidamente por versões mais recentes e o risco da obsolescência é o grande inimigo ainda não dominado. A forma digital, embora aparentemente se mostre bastante atrativa, logo se torna obsoleta, exigindo uma preservação vigiada e permanente, com garantias de recursos materiais para as atualizações necessárias. A necessidade de 
elaboração de um "testamento", de uma política específica de preservação e acesso em que "selecione e nomeie, que transmita e preserve, que indique onde se encontram os tesouros e qual o seu valor", para contribuir para que o sentido e o desejo de preservação, imanente em cada um de nós, se transforme em algo real e positivo, e deixe de ser o espectro que atordoa e frustra a nós diante do fato de que todas as coisas criadas pelo ser humano estão sujeitas às mesmas circunstâncias e acasos que determinam a nossa existência: a perda de tudo que é perecível (HOLLÓS, 2010, p. 28-29).

Deparamo-nos com uma mudança de paradigma que implica reconhecer a conservação preventiva como um meio eficaz de ampliação das possibilidades da preservação documental. Esses documentos, nascidos digitais, constituem-se um desafio de preservação ainda maior. Afinal, grande parte da informação produzida nos dias atuais, em praticamente todas as áreas da atividade humana, será perdida e deixará de se constituir como lugar de memória, a menos que sejam desenvolvidos políticas e mecanismos de gestão e preservação para conservá-la às gerações futuras (HOLLÓS, 2010).

Observa-se, por meio da literatura, que a preservação digital ainda é uma questão nova e suscita discussões acaloradas, mostra-se um ponto sensível a preservação dos conteúdos intelectuais das obras disponibilizadas nos repositórios. Em estudos realizados sobre repositórios institucionais na região Sudeste do Brasil, Weitzel e Mesquista (2015) mostram que ainda não se tem nas instituições a prática de formalizar as políticas de preservação, onde num estudo envolvendo nove instituições apenas possuía uma política de preservação digital formalizada: 
Esse fato pode ser responsável por práticas pobres, tais como o baixo índice do uso de extensões de arquivos de alta adequação de preservação digital e a falta de diversificação nas estratégias de preservação digital, privilegiando: backup; inclusão de metadados; e preservação da tecnologia. (WEITZEL; MESQUISTA, 2015, p. 183).

É preciso pensar não só na preservação do suporte físico, mas também no seu acesso futuro. Das estratégias para a preservação digital hoje destacamos a preservação da tecnologia, emulação, migração, encapsulamento, metadatos, identificadores persistentes, backup, redes de distribuição de preservação digital, e de todos esses mecanismos o mais utilizado no Brasil ainda são os backups (WEITZEL; MESQUISTA, 2015).

\section{ABORDAGEM DISCURSIVA: UM MODELO PARA A CONSTITUIÇÃO DE REPOSITÓRIOS INSTITUCIONAIS}

Habermas afirma que somente pela ação comunicativa é possível conciliar um acordo entre sujeitos livres, pois, é nessa categoria que reside a argumentação livre e a significação intersubjetiva, onde se consideram aspectos de verdade, de sinceridade de retidão e de inteligibilidade (VIZEU, 2011).

Toda interação mediada pela linguística gera uma aprendizagem. É pela linguagem que habita o meio para o ideal entendimento. Nas palavras de Habermas (1990, p. 77), "O esboço do agir comunicativo é um desdobramento da intuição segundo a qual o telos do entendimento habita na linguagem." Para tanto, é preciso fazer entender o conceito de diálogo e discurso empreendidos aqui. O primeiro se dá na interação, na filosofia da consciência no - esclarecimento. E no segundo, pela filosofia da linguagem - uma construção interativa para o entendimento intersubjetivo. Isto é, uma ação para a socialização e o outro para a construção de um entendimento mútuo entre as pessoas. A interação orientada pelo entendimento é denominada como ação comunicativa.

Vizeu (2003) inspirado nos fundamentos da Teoria de Habermas 
sobre a prática comunicativa nas organizações, enquanto espaço de interações linguísticas entre os sujeitos, tendo por referência a mudança do paradigma da filosofia da consciência para o paradigma da linguagem, mudança esta denominada, por Habermas e seu intérpretes, como guinada linguística:

[...] deve ter o pressuposto de que os membros que interagem dentro da organização (assim como em seu ambiente) o fazem a partir de um processo intersubjetivo de troca de significados, onde todos detêm a competência essencial para a consecução e coordenação da ação coletiva. Neste novo foco, o sentido essencial da comunicação é dialógico, e o processo de comunicação monológico (comunicação de cunho apenas informacional) indica comunicação distorcida. (VIZEU, 2003, p. 14).

A hierarquia, por exemplo, é um dos elementos inibidor da ação comunicativa. Dado a necessidade por reciprocidade, a dificuldade psicológica e estrutural gerada pelo pressuposto hierárquico representa um pré-constrangimento para a comunicação intersubjetiva. Assim sendo, apesar de os sistemas hierárquicos atenderem ao interesse pela eficiência, preconizam dificuldades no processo comunicativo. Neste ponto, as estruturas organizacionais flexibilizadas não somente correspondem a alternativas para o problema da dinâmica organizacional, mas também facilitariam a comunicação intersubjetiva. Deste modo, reuniria idéias subjetivas (individuais) em relação ao determinado objeto de estudo, ou na resolução de algum problema, onde se tenta captar uma ideia geral um (consenso), do ponto de vista global de um grupo discursor (VIZEU, 2003).

A teoria habermasiana é apenas uma de muitas abordagens existentes para se avaliar criticamente a questão da comunicação organizacional e sua humanização. Optamos por apresentá-la por entender seu potencial enquanto uma perspectiva sociológica afiliada as vertentes hermenêuticas, vertentes estas que têm observado o papel central da linguagem na explicação da vida social. De resto, apesar de serem relativamente simples as bases do modelo de gestão e 
organização orientado pela racionalidade comunicativa, na prática, este não se estabelece de forma tão fácil. Ao contrário, é enorme o desafio para o gestor implantar esta nova referência, especialmente por que ele é condicionado a viver sob a pressão do resultado, o que faz com que a ação estratégica seja uma opção muito mais interessante no curto prazo. Contudo, se desejamos realmente desenvolver sistemas de gestão éticos e que permitam a emancipação das pessoas sujeitas a estes sistemas, a orientação racional-instrumental destes sistemas deve ser repensado (VIZEU, 2009).

Cabe ressaltar que a tese de Habermas e seus estudos relacionados ao uso da linguagem, são voltados a construção de uma teoria crítica da sociedade e neste contexto a linguagem é entendida enquanto mediadora das relações sociais. Aqui, o que se objetiva é minimamente discernir sobre o que destes estudos habermasianos poderiam contribuir à Ciência da Informação e na construção de repositórios para que esta, por sua vez, pudesse agregar a suas teorias e práticas, concepções que lhe permitissem pensar e agir com a informação e as técnicas processuais em contextos interativos e de comunicação. Para Habermas a interação comunicativa tem uma natureza essencialmente cooperativa e existiriam, conforme o autor, quatro condições que compõem uma situação ideal de discurso, sendo elas a sinceridade, a veracidade, a inteligibilidade e a justificabilidade (GRACIOSO, 2010).

\section{REPOSITÓRIOS INSTITUCIONAIS: DISCURSO E MEDIAÇÃO}

A preocupação com a criação de dispositivos que armazenem e, ao mesmo tempo, garantam o acesso a informação na sua mais variada tipologia, é uma crescente nos dias de hoje. Nesse contexto, o RIDI se mostra como uma ferramenta de grandes potencialidades para auxiliar nesta questão. Tomaél e Silva (2007) afirmam que data de 2002 o desenvolvimento dos repositórios institucionais como uma estratégia apropriada pelas Universidades para assumir o papel de editoras, 
facilitando a disseminação da produção científica no formato digital.

Deste modo os repositórios digitais são entendidos como:

[...] bases de dados online que reúnem de maneira organizada a produção científica de uma instituição ou área temática. Os RDs armazenam arquivos de diversos formatos. Ainda, resultam em uma série de benefícios tanto para os pesquisadores quanto às instituições ou sociedades científicas, proporcionam maior visibilidade aos resultados de pesquisas e possibilitam a preservação da memória científica de sua instituição. Os RDs podem ser institucionais ou temáticos. Os repositórios institucionais lidam com a produção científica de uma determinada instituição. Os repositórios temáticos com a produção científica de uma determinada área, sem limites institucionais. (IBICT, 2015).

Estes repositórios mostram-se ferramentas valiosas para arquivos correntes e intermediários, arquivos permanentes, bibliotecas digitais, acervos de obras de arte digitais e curadorias de dados digitais de pesquisa (BRASIL, 2014).

O RIDI, especificamente, possibilita o gerenciamento de diferentes formatos digitais "[...] para coletar, preservar, indexar e distribuir os itens digitais de ambientes acadêmicos (departamentos, laboratórios, centros, escolas, programas)." (BLATTMANN; WEBER, 2008, p. 467).

Por ser um sistema que adota o protocolo da Iniciativa de Arquivos Abertos (Open Archives Initiative Protocol for Metadata Harvesting - OAI-PMH), o Dspace (já mencionado no item 2) transfere a responsabilidade e os custos das atividades de arquivamento e publicação as instituições que $\mathrm{o}$ adota. Ao refletirem sobre a implementação de repositórios digitais Blattman e Weber (2008) apontam dez itens que devem ser levados em consideração: definições das políticas internas e externas do repositório, identificação da massa documental, auto-arquivamento, disponibilização do conteúdo na internet, utilização de protocolos internacionais (como o OAI-PMH e Dublin Core), estimulação do trabalho colaborativo, preservação do 
conteúdo digital, recuperação da informação, acessibilidade e o aumento da visibilidade internacional a produção contida no repositório, para as autoras estes seriam os pontos que necessitariam de mais atenção para a implementação de repositórios, acrescentamos a essa lista a questão da customização do software adotado, nesse quesito o Dspace se apresenta como uma das melhores plataformas de acesso aberto disponíveis hoje.

O Conselho Nacional de Arquivo (CONARQ) no uso de suas atribuições cria a Resolução n 39 , de 29 de abril de 2014, que:

\footnotetext{
Estabelece diretrizes para a implementação de repositórios digitais confiáveis para a transferência e recolhimento de documentos arquivísticos digitais para instituições arquivísticas dos órgãos e entidades integrantes do Sistema Nacional de Arquivos - SINAR. (BRASIL, 2014).
}

Ao consultarmos a literatura sobre os repositórios digitais, observamos que ela aborda muitos assuntos diferentes, como a implementação, preservação digital, ambientes de aprendizagem, confiabilidade, organização da informação dentre outros assuntos, porém, é observável que a produção sobre a temática adota um enfoque tecnicista, a própria resolução do CONARQ aqui citada é um exemplo disso, onde os aspectos técnicos e tecnológicos sobrepõem-se aos aspectos sociais. Contudo, a experiência tem nos mostrado que apenas focar nos aspectos técnicos não é o suficiente e como reposta a isso temos, cada vez mais, fortes os movimentos de humanização das organizações.

É preciso focar nos processos de mediação, aqui entendida como "Processo de interlocução ou interação entre os membros de uma comunidade, pelo qual se estabelece, alimentam ou restabelecem laços de sociabilidade, constituindo assim o mundo da vida." (RODRIGUES, 2000, p. 84). Dessa forma, o discurso e a mediação podem ser apropriados como dispositivos para a (re)construção dos repositórios digitais, criando um ambiente conversacional propício não apenas para 
a implementação dos repositórios, mas para a contínua alimentação dos mesmos.

Tomaél e Silva (2007) ilustram a importância dos processos de mediação quando afirma que a elaboração de qualquer política de informação, em qualquer esfera que seja, necessita a participação de todos os envolvidos, porque sem um consenso geral sobre os princípios e diretrizes de quem faz o quê, como e quando, não se pode criar fundamentos para a construção da autossuficiência informacional, se não existe meios para resolver as divergências (mediação) a maior parte da energia será desviada para conflitos internos em vez de ser direcionada para lidar com os desafios externos.

Vizeu (2005) afirma que a adoção da TAC tem sido crescente nos estudos organizacionais, desta forma, a criação de um ambiente conversacional mostra-se como uma forma de otimizar a implementação dos repositórios digitais, que precisa de abordagem que consigam dar conta da complexidade inerente aos fenômenos sociais, a TAC, nesse contexto, é utilizada para criar bases teóricas para a construção de formas contrárias ao modelo tradicional de gerência, um modelo baseado numa abordagem discursiva.

A implementação dos repositórios digitais tem sido pautada, até agora, numa razão instrumental, que objetiva uma desnaturalização da condição humana, agindo de forma dominadora (VIZEU, 2005), o que significa que na prática os repositórios são desenvolvidos, assim como as próprias políticas dos repositórios, sem que haja um diálogo com as pessoas responsáveis pela manutenção do mesmo ou seus usuários, o que pode gerar um súbito de animação por parte das instituições que, infelizmente, não dura muito, transformando os repositórios em mais uma ferramenta digital que caí rapidamente no desuso.

Neste momento voltamos nosso olhar para a TAC como um dispositivo de mediação, criando de um ambiente conversacional onde os integrantes ocupam uma posição de igualdade, que estimula uma construção coletiva evolvendo vários setores da organização, o que 
resolveria, por exemplo, o problema da continuidade na alimentação dos repositórios.

\section{CONSIDERAÇÕES FINAIS}

De uma forma geral, para o cumprimento das políticas na Instituição, estabelecerá mecanismos de estímulo, assim como ações de integração que possibilitem evitar duplicações de esforços. Além disso, a implementação de políticas poderá suscitar a elaboração, discussão, regulamentação e estabelecimento de normas e mecanismos específicos de forma a garantir a plena alimentação do repositório institucional e, por conseguinte, a preservação da produção científica institucional (KURAMOTO, 2009).

Os repositórios institucionais são serviços vinculados organicamente aos seus ambientes institucionais; são cumulativos e persistentes e, portanto, têm compromissos fortes com a formação da memória digital acadêmica, com a preservação de longo prazo de materiais de valor contínuo e com os movimentos de livre acesso. Para tal, esses repositórios têm como base tecnológica sistemas abertos e interoperáveis e aderência aos padrões das áreas de Biblioteconomia, Arquivologia, Ciência da Informação e Tecnologia da Informação (MARCONDES, SAYÃO, 2009). Os respectivos profissionais dessas áreas têm o papel de estar atuante na rede de equipe, a todo o momento o diálogo comum entre eles, sem que haja distorção entre o discurso intelectual e do conhecimento prático de cada um. Ressaltamos a necessidade de se pensar a questão, a partir de um ponto de vista discursivo, fugindo de uma visão tecnicista, que tem se mostrado falha a longo prazo.

Acentuamos que o tratamento horizontal é o diferencial e requisito crucial para as Instiutições/Organizações operar sobre estruturas vantajosas e adaptativas. Onde se pode construir, praticar e experiênciar a discursividade. Desempenhando um conjunto de prioridades para os processos organizacionais sob o olhar humanísticos 
e registrando e agindo nos estudos para a aplicação de métodos experimentais.

Pesquisas relacionadas aos repositórios têm se mostrado um extenso campo de exploração dentre variadas investigações específicas. Relacionar esses campos com o modelo teórico e discursos crítico de Habermas multiplica o campo de estudos. Portanto, inicialmente, sugere-se então, como novo tema o de investigar os potenciais das tecnologias da informação, na teoria da ação comunicativa. Num enfoque participativo e crítico dos padrões de softwares em repositórios digitais.

\section{REFERÊNCIAS}

AGGIO, C. SAMPAIO, R. C. Democracia Digital e Participação: Os modelos de consulta e os desafios do Gabinete Digital. In: COCCO, Giuseppe (Org.). Gabinete digital: análise de uma experiência. Porto Alegre, RS: Corag, 2013. 153 p. Disponível em:

$<$ http://gabinetedigital.rs.gov.br/wp/wpcontent/uploads/2013/09/Gabinete-Digital_-An\%C3\%A1lise-de-umaexperi\%C3\%AAncia.pdf>. Acesso em: 22 jun. 2015.

ALVES, M. A. S. Racionalidade e argumentação em Habermas. Revista de Estudos dos Pós-Graduandos em Filosofia: Kínesis, Marília, v. 1, p. 179-195, 2009. Disponível em: <http://www.marilia.unesp.br/Home/RevistasEletronicas/Kinesis/Artigo13 .M.Souza.pdf >. Acesso em: 22 jun. 2015.

ARAGÃO, L. M. de C. Razão comunicativa e teoria social crítica em Jürgen Habermas. Rio de Janeiro: Tempo Brasileiro, 1992.

BLATTMANN, Ursula; WEBER, Claudiane. DSpace como repositório digital na organização. Revista ACB: Biblioteconomia em Santa Catarina, Florianópolis, v.13, n.2, p.467-485, jul./dez., 2008.

BRASIL. CONSELHO NACIONAL DE ARQUIVOS. Resolução $n^{\circ} 39$, de 29 de abril de 2014. Estabelece diretrizes para a implementação de repositórios digitais confiáveis para a transferência e recolhimento de documentos arquivísticos digitais para instituições arquivísticas dos órgãos e entidades integrantes do Sistema Nacional de Arquivos SINAR. Disponível em:<http://www.conarq.arquivonacional.gov.br/media/publicacoes/resol conarq_39_repositorios.pdf> Acesso: 22 jun. 2015. 
GRACIOSO, L. de S. Justificação e a ação de informação no contexto da pragmática virtual. Liinc em Revista, v.6, n.2, setembro, 2010, Rio de Janeiro, p. 286- 300. Disponível em:

$<$ http://revista.ibict.br/liinc/index.php/liinc/article/view/378/243>. Acesso em: 22 jun. 2015.

HABERMAS, J. Técnica e ciência como ideologia. Lisboa: Edições 70, 1987b.

Pensamento pós-metafísico: estudos filosóficos. Rio de Janeiro: Tempo Brasileiro, 1990.

. Teoria do Agir Comunicativo. Tradução Paulo Astor Soethe;

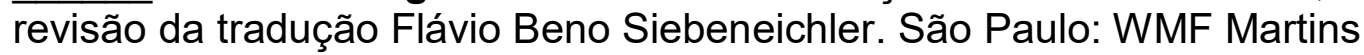
Fontes, 2012. (Racionalidade da ação e racionalização social, 1).

Direito e Democracia: entre facticidade e validade. 2. ed. Rio de Janeiro: Tempo Brasileiro. 2010.

Teoría de la acción comunicativa: complementos e estudios previos. Madrid: Cátedra, 1989.

. Verdade e Justificação: ensaios filosóficos, SP, Loyola, 2004.

HOLLÓS, A. C. Fundamentos da preservação documental no Brasil.

Revista Acervo, Rio de Janeiro, v. 23, n. 2, p. 13-30, jul/dez 2010.

Disponível

em: $<$ http://www.revistaacervo.an.gov.br/seer/index.php/info/article/view/ 8/6>. Acesso em: 22 jun. 2015.

INSTITUTO BRASILEIRO DE INFORMAÇÃOEM CIÊNCIA E TECNOLOGIA. Rio de Janeiro: IBICT, 2015. Disponível em: $<$ http://www.ibict.br/informacao-para-ciencia-tecnologia-einovacao\%20/repositorio-institucional-doibict\%28ridi\%29/apresentacao/?searchterm=ridi>. Acesso em: 22 jun. 2015.

KURAMOTO, H. Repositórios institucionais: políticas e mandatos. In: SAYÃO, Luis Fernando et al. (Org.). Implantação e gestão de repositórios. Salvador: EDUFBA, 2009. Disponível em:

$<$ https://repositorio.ufba.br/ri/bitstream/ufba/473/3/implantacao_repositori o_web.pdf >. Acesso em: 22 jun. 2015.

LIMA, C. R. M. de; CARVALHO, L. dos S.; LIMA, J. R. T. Notas para uma administração discursiva das organizações. DataGramaZero Revista de Ciência da Informação, Rio de Janeiro, v. 11, n. 6, dez. 2010. Disponível em: <http://dgz.org.br/dez10/Art_03.htm>. Acesso em: 22 jun. 2015. 
MAIA, R. C. M. Democracia e a internet como esfera pública virtual: aproximação às condições da deliberação. Associação Nacional dos Programas de Pós-Graduação em Comunicação. 2010. Disponível em: <http://www.compos.org.br/data/biblioteca_1252.pdf >. Acesso em: 22 jun. 2015.

MARCONDES, C. H.; SAYÃO, L. F. Softwares livres para repositórios institucionais. In: SAYÃO, Luis Fernando et al. (Org.). Implantação e gestão de repositórios. Salvador: EDUFBA, 2009. Disponível em: <https://repositorio.ufba.br/ri/bitstream/ufba/473/3/implantacao_repositori o_web.pdf >. Acesso em: 22 jun. 2015.

MORGAN, G. Imagens da organização. 2. ed. São Paulo: Atlas, 2006.

MURAKAMI, Tiago Rodrigo Marçal; FAUSTO, Sibele. Panorama atual dos Repositórios Institucionais das Instituições de Ensino Superior no Brasil. InCID: Revista de Ciência da Informação e Documentação, Brasil, v. 4, n. 2, p. 185-201, dez. 2013. Disponível em: <http://www.revistas.usp.br/incid/article/view/69327>. Acesso em: 18 jun. 2015.

\section{RODRIGUES, A. D. Dicionário breve da informação e da} comunicação. Lisboa: Presença, 2000.

SAYÃO, L. F.; SALES, L. F. Dados de pesquisa: contribuição para o estabelecimento de um modelo de curadoria digital para o país. Instituto de engenharia nuclear. 2013. Disponível em: <http://carpedien.ien.gov.br:8080/bitstream/ien/646/1/DADOS\%20DE\%2 OPESQUISA.pdf>. Acesso em: 22 jun. 2015.

. Curadoria Digital: um novo patamar para preservação de dados digitais de pesquisa. Inf. \& Soc.: Est., João Pessoa, v.22, n.3, p. 179191, set./dez. 2012.Disponível em:

<http://www.ies.ufpb.br/ojs/index.php/ies/article/view/12224/8586>. Acesso em: 22 jun. 2015.

TOMAÉL, M. I.; SILVA, T. E. da. Repositórios institucionais: diretrizes para políticas de informação. In: ENCONTRO NACIONAL DE PESQUISA EM CIÊNCIA DA INFORMAÇÃO, 8., 2007, Salvador. Anais eletrônicos... Salvador: ANCIB, 2007. Disponível em:

$<$ http://www.enancib.ppgci.ufba.br/artigos/GT5--142.pdf>. Acesso em: 22 jun. 2015.

VIZEU, F. Algumas contribuições da teoria da ação comunicativa para a área de organizações. In: ENCONTRO DA ASSOCIAÇÃO NACIONAL DE PÓS-GRADUAÇÃO E PESQUISA EM ADMINISTRAÇÃO (ENANPAD), 27, 2003, Atibaia. Anais eletrônicos... Atibaia: ANPAD, 2003. Disponível em:<http://www.anpad.org.br/diversos/trabalhos/EnANPAD/enanpad_20 03/TEO/2003_TEO106.pdf>. Acesso em: 22 jun. 2015. 
Ação comunicativa e estudos organizacionais, Revista de administração de empresas, São Paulo, v. 45, n. 4, set./dez. 2005.

. Racionalidade Administrativa e Distorção Comunicativa nas Organizações Contemporâneas. In: ENCONTRO DA ASSOCIAÇÃO NACIONAL DE PÓS-GRADUAÇÃO E PESQUISA EM ADMINISTRAÇÃO, 33., 2009, São Paulo. Anais eletrônicos... São Paulo: ANPAD, 2009. Disponível em:<http://www.anpad.org.br/admin/pdf/EOR300.pdf>. Acesso em: 22 jun. 2015.

Uma aproximação entre liderança transformacional e Teoria da Ação Comunicativa. RAM, Rev. Adm. Mackenzie (Online), v.12, n.1, p.53-81, fev. 2011. Disponível em:

$<$ http://editorarevistas.mackenzie.br/index.php/RAM/article/view/1682/26 35>. Acesso em: 22 jun. 2015.

WEITZEL, S. da R; MESQUITA, M. A. A. de. Preservação digital em repositórios institucionais: práticas na região Sudeste do Brasil. Liinc em Revista, Rio de Janeiro, v.11, n.1, p. 181-196, maio 2015. Disponível em: <http://revista.ibict.br/liinc/index.php/liinc/article/view/778/536>. Acesso em: 22 jun. 2015.

\section{Title}

Contributions of discursivity for the construction of digital repositories

\section{Abstract}

Introduction: It discusses the (re)construction of digital repositories, using as example the Repositório Institucional Digital do Instituto Brasileiro de Informação em Ciência e Tecnologia - RIDI, from a discursive perspective adopting the theory of communicative action of Jürgen Habermas.

Objective: To propose a dialogue - mutual understanding - as a device to understand what are the contributions of adopting a discursive approach to the implementation of digital repositories.

Methodology: It adopts a critical approach based on Habermas's theory to discuss the communicative act and the humanization in the organizations.

Results: It is observed that the adoption of a discursive approach has the potential to rethink the implementation and maintenance of digital repositories.

Conclusions: It reflects on the creation of digital repositories, and related issues such as their preservation policies, and points mediation as a way to optimize that implementation.

Keywords: Habermas. Discursive rationalization. Humanization in the organizations. Institutional repositories. 
Clóvis Ricardo Montenegro de Lima; Jobson Francisco da Silva Júnior; Márcio da Silva Finamor

Contribuições da discursividade para a construção de repositórios digitais

\section{Título}

Contribuciones de la discursividad para la construcción de repositórios digitales

\section{Resumen}

Introducción: En esta investigación se discute la (re)construcción de los repositórios digitales, usando como ejemplo el Repositório Institucional Digital del Instituto Brasileño de Información en Ciencia y Tecnología - RIDI, apoyada en la perspectiva de la discursividad con la adopción de la Teoría de la Acción Comunicativa (TAC) de Jürgen Habermas.

Objetivo: Tiene como propuesta la discusión como un dispositivo para comprender cuáles serían las contribuciones de un enfoque discursivo para la implementación de repositórios digitales.

Metodología: Se adopta un enfoque crítico fundamentado en la teoría de Habermas para discutir la acción comunicativa y la humanización en las organizaciones.

Resultados: Se observa que la adopción de un enfoque discursivo presenta potencialidades para replantear la implementación y el mantenimiento de los repositorios digitales.

Conclusiones: En conclusão, eso refleja sobre la constitución de repositorios digitales, y cuestiones correlatas como sus políticas de preservación, y apunta la mediación como una forma de optimizar la implementación de los mismos.

Palabras claves: Teoria de la Acción Comunicativa. Repositórios Institucionales Racionalización discursiva. Humanização en las organizaciones.

Recebido em: 15/03/2015

Aceito em: 10/09/2015 